\title{
BAMBALALÃO: \\ O TEATRO DE BONECOS INTERATIVO NA TV
}

\section{O programa Bambalalão, veiculado pela $T V$ Cultura nos anos 80, deixou uma receita de sucesso ao fundir a linguagem do Teatro de Bonecos à da TV ao vivo; união que permitiu interação criativa $\mathrm{e}$ crítica entre atores, platéia e telespectadores, fundamental à programação infanto-juvenil}

O espírito do Teatro de Bonecos se constitui para mim de muito humor, lúdico por um lado e lírico por outro. Pode ser também dramático como por exemplo nas histórias de samurais do Teatro de Bonecos tradicional japonês - o Bunraku. A crítica e a irreverência são outras fortes características deste tipo de teatro. Um boneco tem direito a dizer grandes verdades ou mentiras sem magoar ou ofender ninguém. Os atos de um boneco são logo perdoados e ficam por conta de sua aparente irresponsabilidade.

A escolha do repertório para crianças ou adultos deve recair em textos com poder de síntese, nos quais a ação predomine sobre a parte falada. Podemos montar espetáculos com peças cujos diálogos sejam fixos ou com roteiros, neles se improvisa o texto do tema proposto. $\mathrm{O}$ conteúdo das peças dependerá da ideologia e programa do grupo de teatro. O Teatro de Bonecos se presta e sempre teve a função de satirizar a sociedade além de sua natural característica de alimentar o imaginário social. No entanto, qualquer que seja a meta de trabalho, este deve levar às crianças, particularmente, a oportunidade de se divertir ativando sua criatividade, raciocínio, poder de análise etc. É preciso não menosprezar, porém valorizar a capaci-

\section{A AUTORA}

Maria Amélia de Carvalho

Atriz, escritora de literatura e teatro infantil, criadora do projeto Bambalalão da TV Cultura e mestranda em Artes Cênicas pela ECA-USP. dade da criança, não usando peças que apresentem soluções fechadas e simplistas em demasia, tramas estereotipadas, pieguismo e linguagem redundante. 
Na história do Teatro de Bonecos grandes dramaturgos e poetas escreveram especialmente para ele. Assim como o boneco, as peças devem ser esquematizadas. O Teatro de Bonecos não pode ser literário, ou seja, baseado somente em texto; ele é, antes de tudo, ação. Um gesto preciso de um boneco comunica mais do que uma frase dita por ele. Os diálogos devem ser simples e curtos. As ações devem conter o elemento surpresa, ser breves e de fácil entendimento.

A improvisação de texto é uma técnica básica para quem faz Teatro de Bonecos. Os textos são enriquecidos com a interferência do público. Tendo um roteiro central as ações podem modificar-se a partir das reações espontâneas da platéia. Entre os estilos do Teatro de Bonecos guarda-se o espírito da Comédia Dell'Arte italiana e da arte do improviso.

Portanto não trabalho muito com texto fixo a não ser em alguns casos, para cinema ou televisão. Contudo é importante o papel do Teatro de Bonecos tradicional de certas culturas, retratando épocas e fatos históricos com textos fixos.

\section{INTERAÇÃO PALCO E PLATÉIA}

O diálogo que um espetáculo de bonecos consegue com o público é uma das características do Teatro de Bonecos. Espetáculos com textos absolutamente fixos podem tornar-se frios. Quando um ator-manipulador movimenta um boneco com a voz de outro ator da equipe, corre-se o risco de quebrar a espinha dorsal da atuação do personagem pois a liberdade de atuação se restringe.

A eficiência de um espetáculo deste tipo começa pela preocupação com o ambiente físico da sala ou espaço ao ar livre, a adequação do projeto e realização do palco, os cenários, bonecos, música, som, iluminação etc.

Porém mesmo quando os titeriteiros têm ambiente adequado, o apoio de um bom tema ou texto e a coordenação de equipe, pode ser que ainda assim o espetáculo não envolva o público. É sinal de que existe um ponto falho no trabalho desenvolvido. Poderá estar faltando a vida dos bonecos - o ponto crucial do teatro de animação.

Dar vida, anima, a um boneco é dar alma ao personagem. Sem isto pode não acontecer a interação palco e platéia.

Nesse caso, interação seria o poder dos atores manipuladores de atuar com sensibilidade para a platéia do momento, com suas particularidades, numa troca de idéias e emoções, resultando um jogo criativo.

Um espetáculo de Teatro de Bonecos relativamente é de fácil transporte e conseqüente mobilidade, atingindo públicos das mais longínquas e variadas comunidades. 


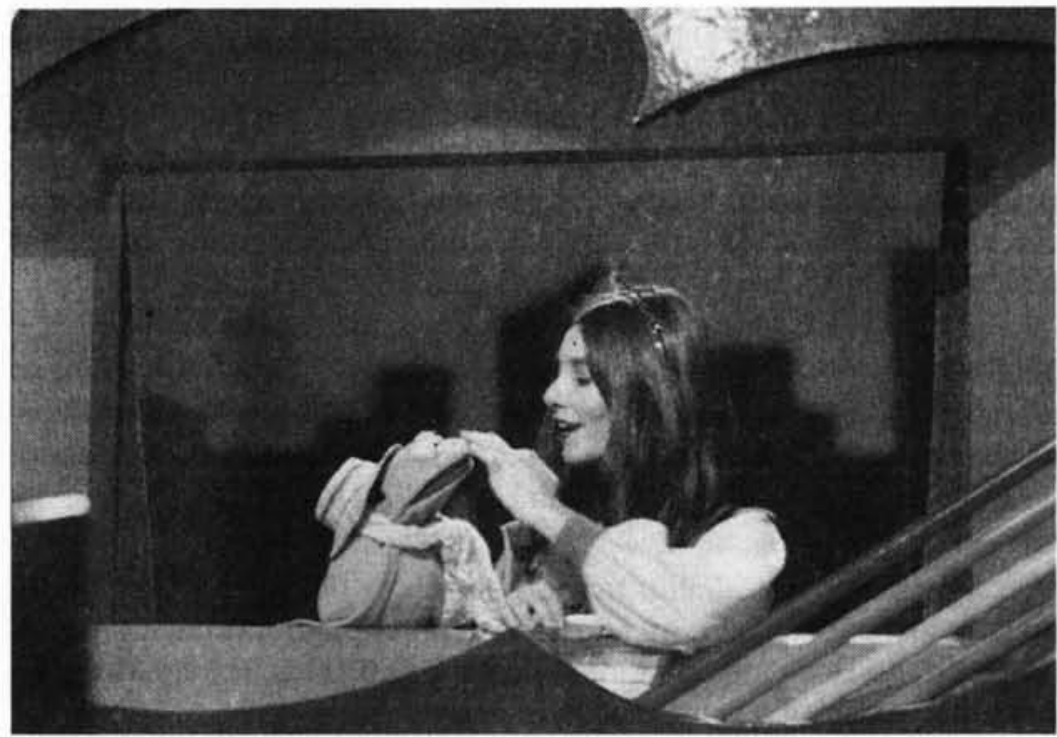

Gigi e o sapo Agapito: um encontro com o príncipe encantado.

$\mathrm{O}$ elenco de bonequeiros deve ter sempre a sensibilidade para intuir a natureza de cada público e de que forma sua atuação poderá render melhor. $\mathrm{O}$ grupo de atores deve perceber até que ponto do trabalho seus textos, ações e personagens podem ser mantidos, adaptados ou afastados. Esta avaliação deve ser feita antes, depois e mesmo durante o espetáculo.

Tanto no teatro-educação, onde o processo criativo da montagem de um espetáculo é mais importante que o resultado, quanto no teatroespetáculo onde acontece o inverso, o verdadeiro sabor de uma apresentação está na interação entre boneco e espectador. Essa ponte deverá criar condições favoráveis para levar as mais variadas mensagens de uma forma aberta na qual o público se sinta envolvido pela ação teatral.

Certamente é esse o sentido da palavra "brincadeira" que é como o povo do Nordeste chama, com muito humor, seu teatro popular de bonecos - o Teatro de Mamulengos.

Volto à velha questão: por que o teatro, mesmo na sua forma mais simplificada, subsiste bravamente depois do aparecimento de veículos de comunicação sofisticados tecnicamente como o cinema e a TV? Certamente porque a presença física dos atores, com ou sem bonecos, fascina e continuará fascinando as platéias do mundo todo.

Como num jogo, cada instante no teatro é energia e mistério e não será jamais o mesmo, quantas vezes se repetir a cena.

Defendo o uso do boneco no cinema com a linguagem do cinema. Na TV com a linguagem da TV. No palco, tradicional ou não, vamos usar o boneco com a linguagem do palco. Teatro de Bonecos é antes de tudo um jogo, ou melhor - uma brincadeira. 


\section{O TEATRO DE BONECOS INTERATIVO E A TV}

No decorrer da rica história do Teatro de Bonecos se desenvolveu uma variada escola de estilos, princípios estéticos, filosóficos e culturais. Novas tendências surgem freqüentemente no Teatro de Bonecos, assim como no Teatro de Formas Animadas.

Na maior parte da minha vivência com Teatro de Bonecos tenho trabalhado com TV ao vivo. Defendo especialmente esta modalidade da TV como uma das alternativas que devem compor um plano geral de programação infanto-juvenil na televisão.

Contudo sou também favorável à existência correlata de bons programas com Teatro de Bonecos que sejam gravados, como por exemplo, o Muppet Show e o Sesame Street (Vila Sésamo), surgidos nos anos 60, produzidos com recursos conjuntos de TV e Cinema, e empregando edição final e outras características de trabalho fechado. Analisando só a produção internacional também destaco o contemporâneo programa Família Dinossauro, pela alta qualidade visual, refinado humor crítico da sociedade e sua moderna tecnologia em teatro de máscaras com controle remoto para a movimentação do jogo fisionômico.

Porém não vou tratar ou analisar aqui esse gênero de teatro caracterizado pela busca da técnica de vanguarda com recursos de cinema, resultando em obras que podem ser exibidas tanto na TV como no cinema ou em videocassete.

Quero defender o Teatro de Bonecos que denomino interativo, tanto no palco como na TV, no qual uso a ação do aqui-agora com a linguagem do teatro improvisacional, entre os atores, assim como a

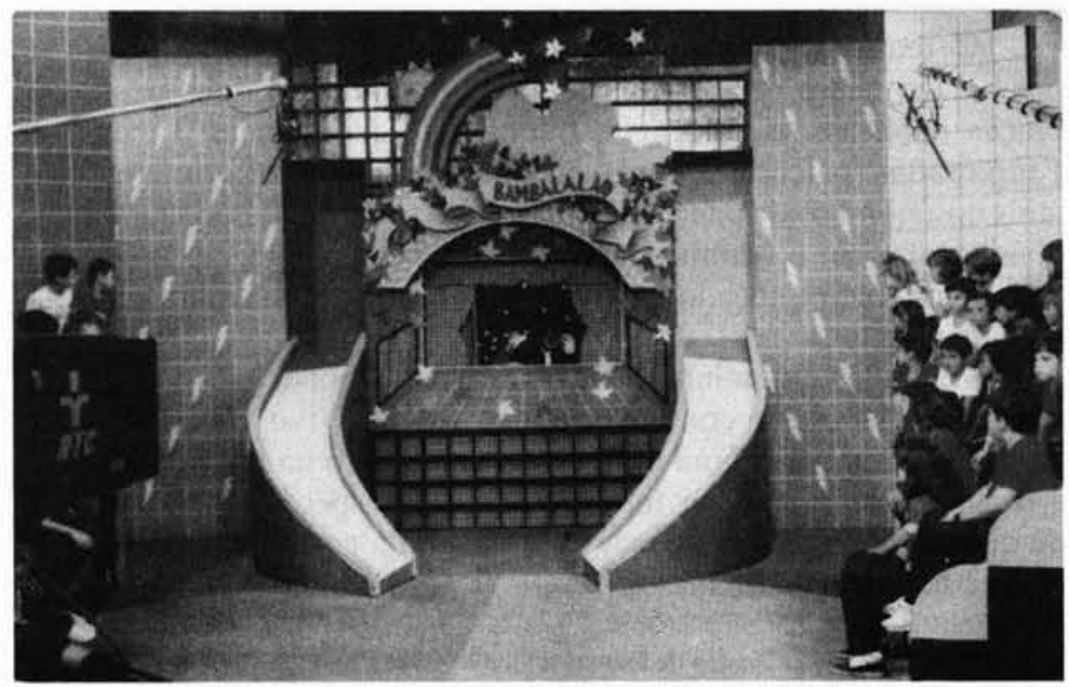

Na TV ao vivo atores, bonecos e platéia em perfeita interação. 
interação entre palco e platéia. Trabalho com o lado criativo e espontâneo do ator-animador de bonecos, para também despertar a espontaneidade da platéia, resultando num jogo de idéias e emoções entre os dois lados do jogo dramático, com Teatro de Bonecos: palco e platéia. Como diz a autora Ana Maria Amaral: "Há no teatro de formas animadas uma característica que é própria também do teatro em geral e que cada vez mais se acentua, que é essa característica de se apresentar para um limitado público. Os espetáculos são propositadamente concebidos para um número reduzido de pessoas. Numa atmosfera de intimidade, cria-se uma nova relação de palco e platéia"'. Ana Maria Amaral tem um vasto e profundo trabalho com Teatro de Bonecos e de Formas Animadas tanto no campo da prática quanto no ensino e pesquisa histórica. Não é o caso de destacar aqui mais trechos de seu importante livro Teatro de formas animadas mas sim a obra como um todo, que revela tão bem o fantástico mundo dos bonecos e das formas animadas.

O Teatro de Bonecos, desde o começo da sua história, caracteriza-se por usar de uma linguagem intimista até pelo tamanho diminuto da maioria dos bonecos de animação e o ator-animador precisa estar próximo fisicamente do espectador, propiciando a interação com a platéia, numa relação de cumplicidade, tanto no diálogo explícito como no implícito.

O teatro improvisacional traz o espectador mais para junto da obra a ser encenada fazendo com que ele participe com idéias e até ações, além da emoção despertada. O espírito do teatro improvisacional sempre teve características próximas do perfil da Obra Aberta ${ }^{2}$ contemporânea que dá espaço à imaginação do espectador enquanto estimula os próprios atores.

O Teatro de Mamulengos do Nordeste do Brasil caracteriza-se por ser um teatro de participação onde o público, normalmente nas praças públicas, se coloca na frente das denominadas Tordas ou Empanadas (palcos desmontáveis que escondem o Mamulengueiro atrás dos biombos de pano). Assim bem de perto o público vibra mais, dialogando com o Mamulengueiro, com seus palpites e interferências até no roteiro traçado - interagindo, enfim, com a obra apresentada no palco.

Pretendo, em minha ação teatral com bonecos, juntar estas duas expressões da comunicação: a TV ao Vivo e o Teatro de Bonecos Interativo numa obra de caráter aberto na qual o processo e o resultado possam ser modificados pelo espectador na tentativa de que ele deixe de ser apenas um consumidor passivo deste veículo de comunicação de massa.

1. AMARAL, Ana Maria. Teatro de formas animadas. São Paulo: EDUSP, 1993, p.303.

2. ECO,Umberto, Obra aberta: forma e indeterminação nas poéticas contemporâneas. São Paulo: Perspectiva, 1976. 288p. 


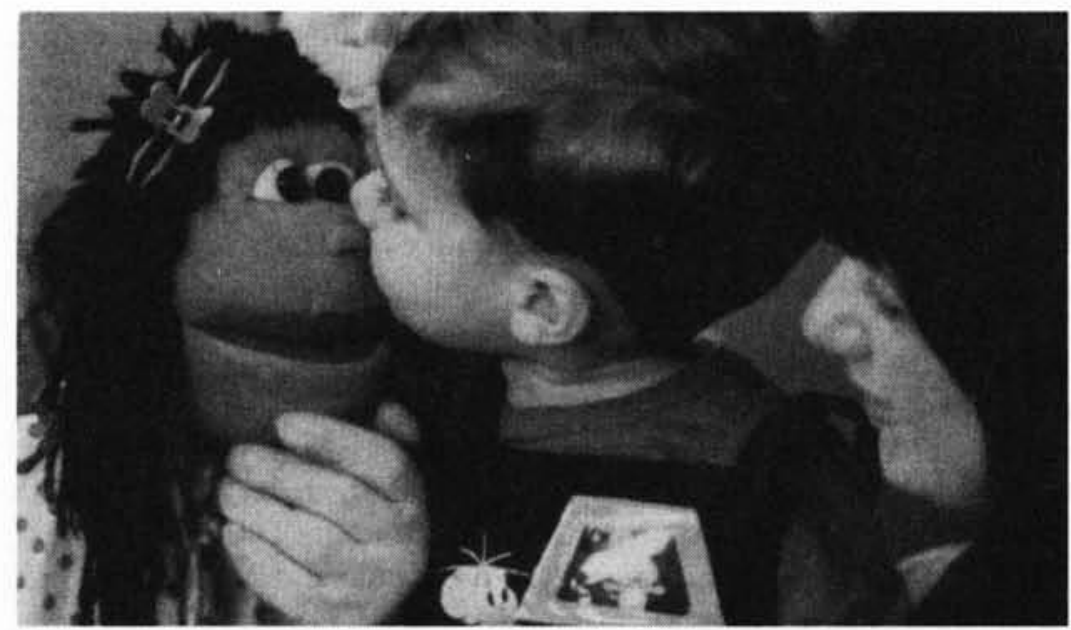

Maria Balinha: um xodó especial com a criançada.

No entanto, como fazer isso se o telespectador está distante? No caso de existir platéia ao vivo nos estúdios de TV, o telespectador em casa se identificará com aquela platéia "piloto". Essa velha estratégia muito usada em programas de auditório em TV, desde o seu nascimento, ainda funciona até hoje na maioria dos programas ao vivo, ou gravados, por conta da eterna lei fascinante da ação teatral do aqui-agora.

Uma linha que funciona como atrativo na TV ao Vivo é o uso de temas da atualidade, temas do noticiário que estão sendo vivenciados pelo telespectador, naquele momento, para que se forme a ponte interativa entre palco e platéia, no caso o Teatro de Bonecos Interativo na TV.

Naturalmente o elemento lúdico e criativo estará sempre nas críticas e sátiras que o Teatro de Bonecos desenvolve, quase sempre, nas suas apresentações.

Quando usamos temas para serem improvisados e a platéia sente que deve interferir, as câmaras de TV fixas ou portáteis estarão sempre a postos para captar em close e registrar o lado espontâneo dos espectadores presentes na platéia dos estúdios de TV, captando suas mínimas expressões.

No Bambalalão, série de programas diários de TV ao vivo, infanto-juvenil, da Rádio e TV Cultura, onde atuei por mais de 2.000 programas de 1982 a 90 , foram instalados monitores de TV para a platéia e principalmente monitores virados para os atores manipuladores para podermos controlar nossos próprios bonecos no vídeo e captar a reação imediata da platéia, inclusive com o auxílio de microfones volantes. Nós, atores animadores de bonecos, respondíamos a cada interferência significativa comandando a ponte interativa - palco e platéia. 
Por outro lado, crianças, jovens ou adultos da platéia eram convidados a entrar no cenário especial dos bonecos para cenas improvisadas, ou também para participar de pequenas cenas nas peças de teatro ao lado dos bonecos com temas definidos previamente. Durante o programa Bambalalão como um todo, os apresentadores e atores também atuavam lado a lado com os bonecos numa relação criativa entre a fantasia e a realidade.

Como poderia o telespectador em casa participar dessa relação interativa no Teatro de Bonecos pela TV? Pela minha experiência constatei que o público em casa, além de se identificar com os bonecos, se identifica com a reação da platéia do estúdio com bastante facilidade, quebrando a "quarta parede" do teatro que nesse caso seria a tela de plástico do visor de um aparelho de TV. Esta chamada telinha ora aproxima o espectador da realidade, ora dá a perfeita ilusão da mais pura magia.

No Bambalalão tínhamos também muitos outros tipos de interação com o público de casa: por exemplo, um pequeno atelier de artes plásticas e artesanato onde ensinávamos várias técnicas de arte apropriadas para crianças. Aí também ensinávamos a fazer teatro de bonecos com técnicas de papier maché, ou espuma, pano, madeira etc. Os bonecos atuavam em variadas cenas diárias como personagens fixos do programa participando de esquetes, entrevistas com convidados, pequenas peças ou histórias dramatizadas, leitura de cartas, noticiário e também vários tipos de jogos com o telespectador. Os bonecos, por exemplo, passavam pelo palco segurando objetos diferenciados para que depois o público descobrisse como estava sua memória e quantos objetos tinham conseguido observar ou não. A música e a dança eram uma constante na vida dos bonecos.

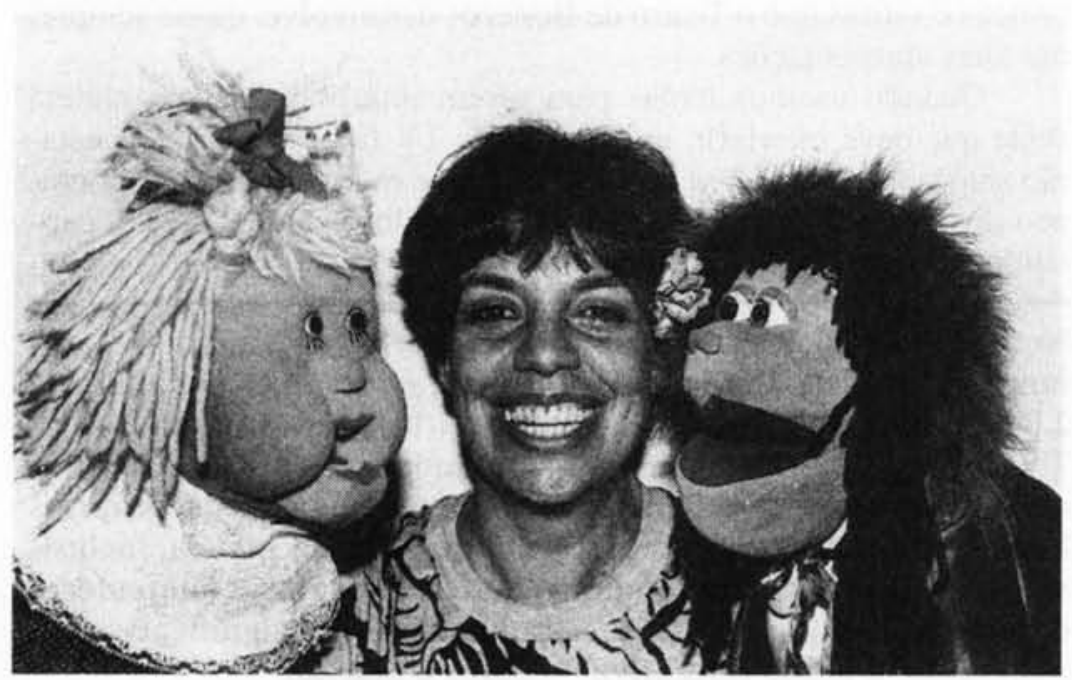

Maria Amélia, a Memélia do Bambalalão, com seus bonecos Xoxa e Maria Balinha. 
O retorno do trabalho realizado no Bambalalão resultou animador. Um dos índices era o material recebido via correspondência ou pessoalmente, que testemunhava essa relação de participação, como: sugestões, críticas, textos para Teatro de Bonecos, contos, histórias, curiosidades, desenhos etc.

Muito significativo e importante era quando chegavam às nossas mãos bonecos ensinados por mim através da TV e que eram feitos em casa pelo telespectador, levando-o a atuar com Teatro de Bonecos. Esses fatos demonstravam que nosso público era incentivado e participava de atividades que resultavam interativas entre a TV e o telespectador.

Enfim nosso público era estimulado a sair de atitudes passivas e contemplativas, frente a uma tela de TV, atitudes que podem dar uma carga exagerada de informação prejudicando, possivelmente, sua capacidade natural de ação.

\section{A PALAVRA DOS BONECOS}

Para a finalização vou dar a palavra aos bonecos, os maiores interessados neste caso. A questão formulada, a partir da minha hipótese, é a seguinte:

- Se o Teatro de Bonecos no palco, ao vivo, está mais próximo da platéia, estará a TV ao Vivo, com Teatro de Bonecos, mais próxima do público?

- Sim, nossa resposta é afirmativa. Queremos defender nosso território no palco tanto quanto na TV, este poderoso veículo eletrônico de comunicação. Reivindicamos sempre mais espaço para nossa ação na era da comunica-ação. 